\title{
$\mathrm{BMC}$
}

\section{Research Notes}

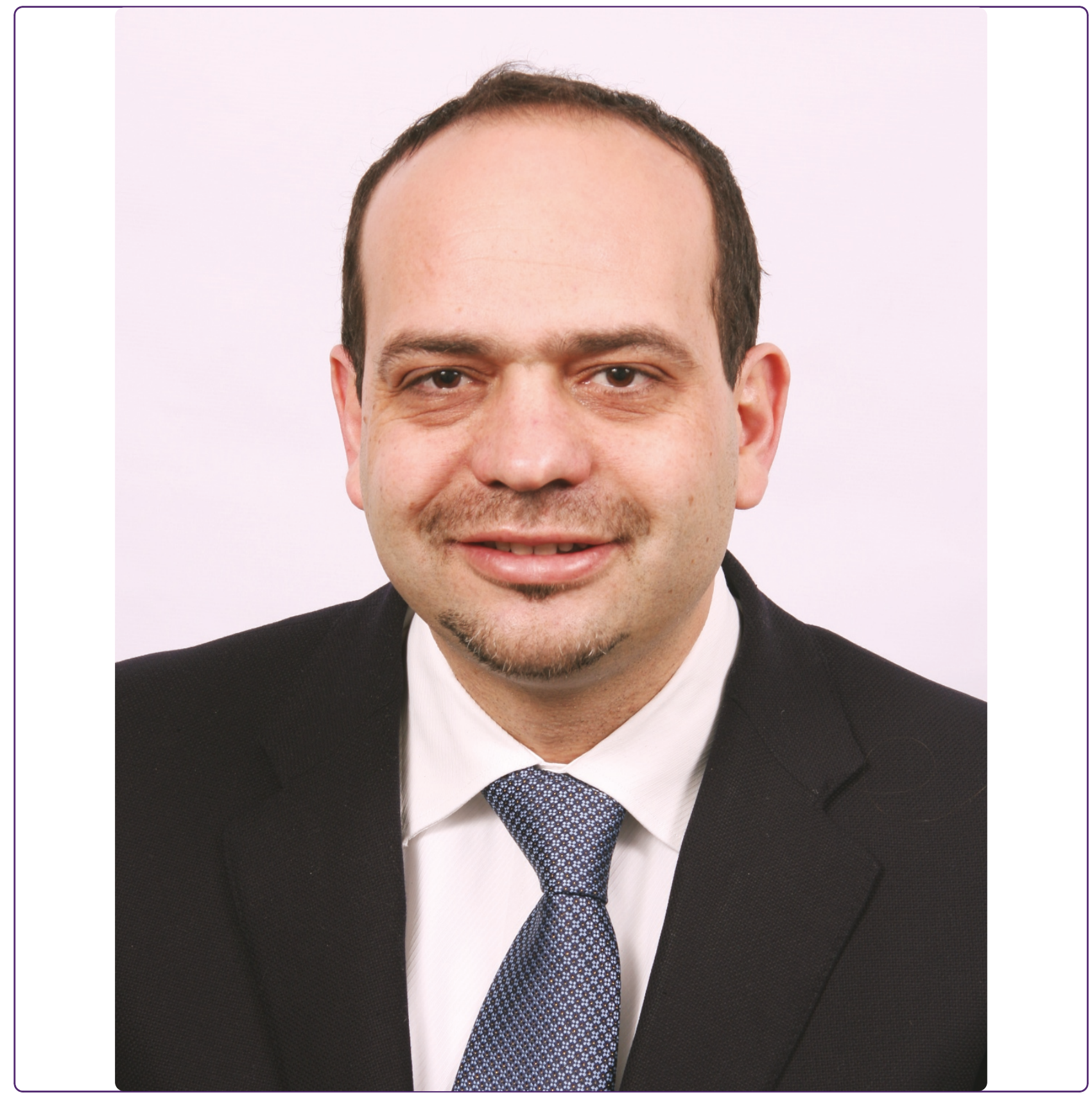

\section{Antibiotics prescribing practices in oral}

implantology among jordanian dentists. A cross sectional, observational study

AbuKaraky et al. 


\title{
Antibiotics prescribing practices in oral implantology among jordanian dentists. A cross sectional, observational study
}

\author{
Ashraf E AbuKaraky ${ }^{1 *}$, Khaldoon Abu Afifeh², Adel A Khatib ${ }^{3}$, Nadiajda O Khdairi ${ }^{3}$, Hanan M Habarneh ${ }^{3}$, \\ Waleed KH Ahmad ${ }^{3}$, Ahmad AS Hamdan ${ }^{1}$ and Faleh A Sawair ${ }^{1}$
}

\begin{abstract}
Background: In oral implantology, there is no consensus on the most appropriate regimen for antibiotics prescribing, the decision to prescribe antibiotic is usually based on procedure, patient and clinician related factors. The aim of this study was to investigate the rationale of antibiotic prescribing among Jordanian clinicians who practice oral implantology.

Findings: The target sample for the study was the 250 Jordan Dental Implant Group members. A five page questionnaire contained 41 questions, both closed and open questions were used to collect data. Statistical analysis was performed using SPSS Windows 16.0 (SPSS Inc., Chicago, IL, USA). Descriptive statistics were generated. The response rate was (70.4\%) 176/250. Mean age was $37.2 \mathrm{yrs,} \mathrm{49.4 \%} \mathrm{always} \mathrm{prescribe} \mathrm{antibiotics} \mathrm{mainly} \mathrm{oral}$ amoxicillin and amoxicillin with clavulinic acid. Antibiotics prescribing increased with flap raising, multiple implants and sinus or bone augmentation. Patient medical condition, periodontitis and oral hygiene were the most important clinical factors in antibiotic prescribing, non-clinical factors were; reading scientific materials, courses and lectures, knowledge gained during training, and the effectiveness and previous experience with the drug.
\end{abstract}

Conclusions: Wide variations in antibiotics types, routes, dose and duration of administration were found. Recommendations on antibiotic prescribing are needed to prevent antibiotic overprescribing and misuse.

Keywords: Antibiotics, Dental Implants, Cross Sectional Study

\section{Introduction}

The practice of oral implantology has been expanding widely over the last few decades, and more patients and dental practitioners are showing interest in this field $[1,2]$. High success rates reported in oral implantology but failure which may have a devastating effect on both patient and clinician still occur. Several studies have investigated causes of failure and recommended measures to reduce its chances [3-9]. Infection has been implicated as one of the main reasons behind early implant failure [10], and whereas some studies found no advantage of antibiotics in ordinary dental implants insertion [11-13], many others found the contrary

\footnotetext{
* Correspondence: a.abukaraky@ju.edu.jo

'Department of Oral and Maxillofacial Surgery, Oral Medicine, Oral Pathology, and Periodontology, Faculty of Dentistry, The University of Jordan, Amman, Jordan

Full list of author information is available at the end of the article
}

[14-16]. Various antibiotic regimens have been suggested; pre-operative prophylactic single or multiple doses, post operative single or multiple doses for several days or a preoperative followed by post operative doses [17-19].

Over prescribing antibiotics has a negative results on the general health and economy, therefore the proper selection of antibiotic regimen in clinical practice has a great value ${ }^{20}$. The clinician decision to prescribe an antibiotic or not for a certain procedure is usually based on several factors, some factors are procedure related; the type, site, complications, sterility and duration of the procedure [21,22], patient related; dental and medical history, drug allergies and cost $[21,22]$ and clinician related; the clinician knowledge, experience, education and working environment $[22,23]$. Regulating bodies had worked on guidelines of antibiotics prescribing for several surgical and medical interventions [24-30], the guidelines aid practitioners to 
prescribe antibiotics only when indicated and in choosing the most effective antibiotic type and dose, thus help reducing the chances of infection and the harm of antibiotics over prescribing [31,32].

In Jordan, oral implantology is practiced in the private sector, the two University Hospitals, the Royal Military Medical Services Hospitals and recently in some of the public hospitals. Jordan is a Middle Eastern country with a population of around 6 millions served by around 7000 dentists. Although it is not obligatory, most dentists who practice oral implantology in Jordan are members of the Jordan Dental Implant Group (JDIG). It had been shown that the Jordanian general dental practitioners (GDPs) inappropriately prescribed antibiotics and poorly adhered to recommended guidelines for optimum dosage and course duration [34]. No previous studies had investigated the antibiotic practice among Jordanian dentists who practice oral implantology, and up to our knowledge no other published studies had investigated this field in other countries.

The aim of this study was to investigate the rational of antibiotic prescription among Jordanian clinicians who practice oral implantology, and to investigate the influence of the procedure, patient and clinician factors on the selection of the type, dose, duration and method of administration of the antibiotic.

\section{Findings}

\section{Subjects and Methods}

The study was an observational study based on information collected from dentists who are members in the Jordan Dental Implant Group, therefore no ethical approval was obtained and the participants were not consented for participation in the study. The target sample was the JDIG members, as most of the Jordanian dentists who practice oral implantology are JDIG members and JGDI represent all sectors that provide the oral implantology service in Jordan. The exact number of dentists who practice oral implantology is not known but it is not expected to exceed significantly the number of the JDIG members which is currently 250, 137 are general dental practitioners (GDP) and 113 are specialists; mainly oral surgeon, prosthodontists and periodontists. A list of the names addresses and telephone numbers of the JGDI members was obtained from the JDIG, members were informed about the study by a telephone call and if agreed, a specifically designed questionnaire was sent by hand and collected a week later. Members who did not complete the questionnaire after the first week were reminded to do so by a telephone call after two weeks and again after four weeks. In case of no positive response after the third follow up call the member was considered non-responsive.

The 5 page questionnaire (additional file 1) was composed of four sections and contained 41 questions, both closed and open questions were used. The first section included questions regarding personal data, education details, work environment and level of experience in oral implantology. The second section was composed of a table with a list of the different oral implantology related procedures and questions that describe the antibiotic protocol followed in each case.

The third section included questions regarding the factors affecting decision of antibiotic prescription, the stem question was whether in all cases of dental implant insertion antibiotics are prescribed, if the answer was no, then the clinician was asked to specify whether the presence of systemic disease, oral hygiene, presence of periodontal disease, smoking and dental implant type (brand name) affect his or her decision. The fourth section was composed of two parts, the first part included open questions where clinicians are asked to write the type, dose, method of administration and duration of the antibiotic they routinely prescribe preoperatively, postoperatively or both in dental implant insertion for healthy individuals not allergic to any medications. In the second part the clinicians where asked if their choice of an antibiotic regimen was affected by the patient preference, reading scientific materials, knowledge gained during undergraduate or postgraduate training, attending courses or lectures, availability of the drug in the nearby pharmacy, advertisement, cost of the antibiotic, recommendation of other colleagues, previous experience with the drug and to specify if there were other factors.

Statistical analysis was performed using SPSS for Windows release 16.0 (SPSS Inc., Chicago, IL, USA). Descriptive statistics were generated.

\section{Results}

Of the 250 JDIG members to whom the structured questionnaires were distributed, $176(70.4 \%)$ returned answered questionnaires. Four of these answered questionnaires were excluded because of missing data. The demographic and professional characteristics of the 172 respondents are shown in Table 1 . The mean age was $37.2 \pm 8.5$ years (range 23-65 years) and mean experience with dental implantology was $6 \pm 4.3$ years (range 1-20 years) with an average number of implant inserted of $271 \pm 664$ (range 15000 implants). Table 2 shows the antibiotics prescription choices of the 172 surveyed dentists in different dental implantology procedures in healthy patients. When asked whether they prescribe antibiotics for all dental implant insertion irrespective of the patient's medical or dental condition, $49.4 \%$ of surveyed dentists answered yes. Of those who answered no to this question, the decision was mainly affected by the presence of systemic disease (91\%), periodontitis (86\%), poor oral hygiene (77\%), and to lesser extent smoking (48\%) and the brand name of the dental implant system (14\%). 
Table 1 Demographic and professional characteristics of participating members of the Jordanian Dental Implant Society

\begin{tabular}{|c|c|c|c|}
\hline Variable & & $\mathrm{n}$ & $\%$ \\
\hline \multirow[t]{2}{*}{ Gender } & Male & 153 & 89.0 \\
\hline & Female & 19 & 11.0 \\
\hline \multirow[t]{4}{*}{ Age (years) } & $\leq 30$ & 41 & 23.8 \\
\hline & $31-40$ & 85 & 49.4 \\
\hline & $41-50$ & 32 & 18.6 \\
\hline & $>50$ & 14 & 8.1 \\
\hline \multirow[t]{3}{*}{ Level of education } & Bachelor & 89 & 51.7 \\
\hline & Master & 66 & 38.4 \\
\hline & PhD/or equivalent & 17 & 9.9 \\
\hline \multirow[t]{5}{*}{ Specialty } & GDP & 96 & 55.8 \\
\hline & Oral surgeon & 43 & 25.0 \\
\hline & Prosthodontist & 13 & 7.6 \\
\hline & Periodontist & 16 & 9.3 \\
\hline & Others & 4 & 2.3 \\
\hline \multirow[t]{5}{*}{ Country of most recent qualification } & Jordan & 78 & 45.3 \\
\hline & Other Arab countries & 42 & 24.4 \\
\hline & Eastern Europe & 22 & 12.8 \\
\hline & Asia & 6 & 3.5 \\
\hline & USA/Western Europe & 24 & 13.9 \\
\hline \multirow[t]{4}{*}{ Area of employment } & Private practice & 135 & 78.5 \\
\hline & University hospital & 10 & 5.8 \\
\hline & Military hospital & 15 & 8.7 \\
\hline & Public hospital & 12 & 7.0 \\
\hline \multirow[t]{2}{*}{ Attended courses on use of antibiotics in dental implantology } & Yes & 102 & 59.3 \\
\hline & No & 70 & 40.7 \\
\hline \multirow[t]{2}{*}{ Read scientific material on use of antibiotics in dental implantology } & Yes & 137 & 79.7 \\
\hline & No & 35 & 20.3 \\
\hline \multirow[t]{3}{*}{ Experience with implants (years) } & $<5$ & 80 & 46.5 \\
\hline & $5-10$ & 70 & 40.7 \\
\hline & $>10$ & 22 & 12.8 \\
\hline \multirow[t]{4}{*}{ Number of implants inserted } & $<50$ & 66 & 38.4 \\
\hline & $51-100$ & 38 & 22.1 \\
\hline & $101-200$ & 22 & 12.8 \\
\hline & $>200$ & 46 & 26.7 \\
\hline
\end{tabular}

Amoxicillin plus Clavulanic acid or amoxicillin alone were the most common preoperative and postoperative antibiotics prescribed, the routes of administration, the dosages, frequencies and the length of the courses are shown in Table 3. Other antibiotics such as Clindamycin, Lincomycin, Metronidazole, penicillin, cephalosporins, or combinations of Amoxicillin and Metronidazole, Clindamycin and Lincomycin, Amoxicillin plus Clavulanic acid and Metronidazole, Amoxicillin and Clindamycin, Amoxicillin and Erythromycin, or Amoxicillin plus Clavulanic and Clarithromycin and Azithromycin were also prescribed by some participants. The non-clinical factors influencing the choice of the antibiotic course prescribed are shown in Table 4.

\section{Discussion}

The sample was representative of all the sectors that provide the oral implantology service in Jordan, and it was clear from the results that young practitioners had more interest in oral implantology and slightly less than half of the service providers were specialists with postgraduate degrees, most of them work in the private sector and many were interested in continuous education. Similar findings related to the increased interest of young generations in oral implantology had been found in other studies in Hong Kong [1] and Switzerland [34].

Antibiotics prescribing was influenced by flap raising, number of implants inserted, the timing of implant insertion in the presence or absence of active infection, 
Table 2 Antibiotic prescription choices of 172 surveyed dentists in different dental implant procedures in healthy patients

\begin{tabular}{|c|c|c|c|c|c|}
\hline \multirow[b]{2}{*}{ Procedure } & \multicolumn{5}{|c|}{ Antibiotic choice } \\
\hline & $\begin{array}{l}\text { I do not prescribe } \\
\text { antibiotic for this } \\
\text { procedure. } \\
\text { n (\%) }\end{array}$ & $\begin{array}{l}\text { I prescribe only } \\
\text { preoperative } \\
\text { antibiotic. } \\
\mathrm{n}(\%)\end{array}$ & $\begin{array}{l}\text { I prescribe only } \\
\text { postoperative } \\
\text { antibiotic. } \\
\mathrm{n}(\%)\end{array}$ & $\begin{array}{l}\text { I prescribe pre- } \& \\
\text { postoperative } \\
\text { antibiotics. } \\
\text { n (\%) }\end{array}$ & $\begin{array}{l}\text { I did not do } \\
\text { this } \\
\text { procedure. } \\
\text { n (\%) }\end{array}$ \\
\hline $\begin{array}{l}\text { Straight forward single implant } \\
\text { case without raising a flap } \\
\text { (flapless). }\end{array}$ & $47(27.3)$ & $8(4.7)$ & $41(23.8)$ & $21(12.2)$ & $55(32.0)$ \\
\hline $\begin{array}{l}\text { Straight forward single implant } \\
\text { case with raising a flap. }\end{array}$ & $26(15.1)$ & $20(11.6)$ & $80(46.5)$ & $40(23.3)$ & $6(3.5)$ \\
\hline $\begin{array}{l}\text { Straight forward multiple flapless } \\
\text { implant case. }\end{array}$ & $19(11.0)$ & $14(8.1)$ & $47(27.3)$ & $31(18.0)$ & $61(35.5)$ \\
\hline $\begin{array}{l}\text { Straight forward multiple implant } \\
\text { case with raising flaps. }\end{array}$ & $10(5.8)$ & $11(6.4)$ & $73(42.4)$ & $60(34.9)$ & $18(10.5)$ \\
\hline $\begin{array}{l}\text { Immediate implant placement in } \\
\text { absence of active infection. }\end{array}$ & $16(9.3)$ & $12(7.0)$ & $50(29.1)$ & $54(31.4)$ & $40(23.3)$ \\
\hline $\begin{array}{l}\text { Immediate implant placement in } \\
\text { presence of active infection. }\end{array}$ & $4(2.3)$ & $9(5.2)$ & $21(12.2)$ & $75(43.6)$ & $63(36.6)$ \\
\hline Internal sinus elevation. & $11(6.4)$ & $8(4.7)$ & $44(25.6)$ & $64(37.2)$ & $45(26.2)$ \\
\hline External sinus elevation. & $3(1.7)$ & $7(4.1)$ & $38(22.1)$ & $62(36.0)$ & $62(36.0)$ \\
\hline Bone augmentation. & $9(5.2)$ & $5(2.9)$ & $43(25.0)$ & $72(41.9)$ & $43(25.0)$ \\
\hline $\begin{array}{l}\text { At time of gingival former } \\
\text { (healing abutment) insertion. }\end{array}$ & $127(73.8)$ & $4(2.3)$ & $7(4.1)$ & $8(4.7)$ & $26(15.1)$ \\
\hline At time of impression taking. & $133(77.3)$ & $0(0)$ & $4(2.3)$ & $8(4.7)$ & $27(15.7)$ \\
\hline At time of crown delivery & $132(76.7)$ & $0(0)$ & $5(2.9)$ & $8(4.7)$ & $27(15.7)$ \\
\hline
\end{tabular}

Table 3 Examples of most commonly prescribed post-operative antibiotics by survey dentists

\begin{tabular}{|c|c|c|c|}
\hline $\begin{array}{l}\text { Pre-Operative Antibiotic } \\
\text { (number)* }\end{array}$ & $\begin{array}{l}\text { Route of administration } \\
\text { (number)* }\end{array}$ & \multicolumn{2}{|l|}{ Dose (number)* } \\
\hline \multirow[t]{2}{*}{ Amoxicillin (32) } & I.M (1) & \multicolumn{2}{|c|}{$500 \mathrm{mg}(1)$} \\
\hline & Oral (31) & \multicolumn{2}{|c|}{500 mg (15); 1000 mg (9); 2000 mg (7) } \\
\hline \multirow{2}{*}{$\begin{array}{l}\text { Amoxicillin + Clavulanic acid } \\
\text { (39) }\end{array}$} & I.M (1) & \multicolumn{2}{|c|}{$1000 \mathrm{mg}(1)$} \\
\hline & Oral (38) & \multicolumn{2}{|c|}{375 mg (1); 625 mg (23); 1000 mg (11); 2000 mg (3) } \\
\hline $\begin{array}{l}\text { Post-Operative Antibiotic } \\
\text { (number)* }\end{array}$ & Dose (number)* & $\begin{array}{l}\text { Daily frequency } \\
\text { (number)* }^{*}\end{array}$ & Course duration (number)* \\
\hline \multirow[t]{4}{*}{ Amoxicillin (23) } & $500 \mathrm{mg}(17)$ & 3 times (17) & 3 days (3); 4 days (2); 5 days (7); 7 days (5) \\
\hline & 1000 mg (6) & Once (1) & One day (1) \\
\hline & & 3 times (1) & 5 days $(1)$ \\
\hline & & Twice (4) & 5 days $(2) ; 6$ days $(1) ; 10$ days (1). \\
\hline \multirow{8}{*}{$\begin{array}{l}\text { Amoxicillin + Clavulanic acid } \\
\text { (49) }\end{array}$} & 375 mg (1) & 3 times (1) & 5 days $(1)$ \\
\hline & 500 mg (1) & 3 times (1) & 5 days $(1)$ \\
\hline & 625 mg (28) & Twice (4) & 7 days (4) \\
\hline & & 3 times (24) & $\begin{array}{l}3 \text { days (2); } 4 \text { days (2); } 5 \text { days (10); } 6 \text { days (2); } 7 \text { days (7); } \\
8 \text { days (1). }\end{array}$ \\
\hline & 1000 mg (17) & Once (1) & 3 days $(1)$ \\
\hline & & Twice (16) & $\begin{array}{l}1 \text { days ( }(1) ; 3 \text { days (2); } 4 \text { days (2); } 5 \text { days (7); } 6 \text { days (1); } 7 \\
\text { days (3). }\end{array}$ \\
\hline & $1250 \mathrm{mg}(1)$ & Twice (1) & 8 days $(1)$ \\
\hline & $1875 \mathrm{mg} \mathrm{(1)}$ & Once (1) & 1 day (1) \\
\hline
\end{tabular}

Note: all post-operative antibiotics were administered per oral route. Note: $(n)^{*}$ number of surveyed dentists who prescribed the antibiotic. 
Table 4 Non-clinical factors affecting the choice of the antibiotic course prescribed by the surveyed dentists for dental implant procedures

\begin{tabular}{cc}
\hline FACTOR & YES (\%) \\
\hline - Patient's preference & 25 \\
\hline $\begin{array}{c}\text { - Reading scientific materials (e.g., books, articles, } \\
\text { internet) }\end{array}$ & 86.6 \\
\hline $\begin{array}{c}\text { - Knowledge gained during undergraduate or } \\
\text { postgraduate training }\end{array}$ & 86 \\
\hline - Attending courses and lectures & 84.9 \\
\hline - Availability in the nearby pharmacy & 24.4 \\
\hline $\begin{array}{c}\text { - Advertisement (free samples, medical } \\
\text { representatives, ... etc) }\end{array}$ & 16.3 \\
\hline - Cost of the antibiotic & 36 \\
\hline - Recommended by other colleagues & 43 \\
\hline - Effectiveness and previous experience with the drug & 84.3 \\
\hline
\end{tabular}

bone augmentation and sinus lifting procedures. Although no evidence could be found in the literature, the participants in this study had considered the flap type, number of implants and the timing of implant insertion as factors for antibiotic prescribing. An interesting finding in the study was that $13 \%$ of the participants prescribe antibiotics at time of gingival former insertion and more interesting was that around $8 \%$ prescribe antibiotics at time of impression taking and at time of crown delivery. On the other hand, regarding timing of antibiotic prescribing, although the pre-operative administration of $2 \mathrm{~g}$ amoxicillin had been recommended to reduce chances of implant failure [35,36], and although the benefit of postoperative administration of antibiotics if preoperative dose had been given was not confirmed [19], in our study few participants prescribe antibiotics pre-operatively compared to postoperatively and a good percentage of participants prescribe antibiotics pre and post-operatively even for simple procedures such as straight forward single implant insertion in healthy individual.

The participants in this study were nearly equally divided on whether antibiotics should always be prescribed prior to implant insertion regardless of any possible related factors. This does reflect the conflicting results and opinions found in the literature regarding oral implantology and antibiotics [11-16]. For participants who do not always prescribe antibiotics, all clinical factors taken in consideration in prescribing antibiotics except for the brand of the implant system used, can be related to increased tendency of infection due to systemic or local reasons. The relation between the implant system brand name and antibiotic prescribing was difficult to understand and the authors were unable to explain. On the other hand, with the exception of patient preference and availability in nearby pharmacy, the non-clinical factors influenced the clinician decision on prescribing and choosing antibiotics were similar to what had been found in other studies made on different medical specialities and for different medical interventions [21-23].

Wide variations in the types, routes, dose and duration of administration of antibiotics were found in the study, both amoxicillin and amoxicillin with calvulinic acid were most frequently used antibiotics pre-operatively or postoperatively. The two antibiotics are widely used in oral implantology and their role in reducing implant failure was investigated in several clinical trials [12,14-16,18,19,35,36]. Although there is no consensus yet on the most appropriate regimen for antibiotics prescribing in dental implant insertion, present evidence suggest that when compared to patients having no antibiotics, patients given a single dose of $2 \mathrm{~g}$ amoxicillin one hour prior to dental implant insertion might experience less implant failure [36]. Several studies found no benefit in prescribing postoperative antibiotics in patients given preoperative $2 \mathrm{~g}$ amoxicillin $[18,19]$, and similar early failure rates were found whether patients had a single preoperative $2 \mathrm{~g}$ amoxicillin one hour prior to surgery or had only postoperative amoxicillin and clavulinic acid $625 \mathrm{mgs}$ three times daily for five days [19].

Other antibiotic regimen used included clindamycin, lincomycin, metronidazole, penicillin, cephalosporins, and some participants followed antibiotic regimens which included a combination of two or three drugs. One familiar combination which had been widely used in dentistry, was amoxicillin and metronidazole [37-39], but other combinations as Amoxicillin and Clindamycin, Amoxicillin and Erythromycin or Amoxicillin plus Clavulanic and Clarithromycin and Azithromycin might not be only unnecessary but might also be harmful for the patient and may encourage the emergence of resistant bacterial strains $[31,32]$.

\section{Conclusions}

Based on the result of this observational study, the main oral implantology service providers were young clinicians, many possess high level of education and had put effort to obtain knowledge mainly by reading scientific materials and attending courses. Despite this, wide variations in antibiotic prescribing practices were found, and some practices may not be justified as it might be considered as antibiotic overprescribing and more importantly might be harmful on the patient. In the authors opinion, recommendations on antibiotic prescribing are needed from international oral implantology regulating bodies based on the available evidence in the literature to help clinicians avoid antibiotic misuse, and meanwhile it might be sensible to suggest that for dental implant insertion, clinicians might give no antibiotics, a single preoperative dose or a short postoperative course. 


\section{Additional material}

Additional file 1: Questionnaire. 5 page questionnaire composed of four sections and contains 41 questions.

\section{Acknowledgements}

The authors would like to thank the board of the Jordan Dental Implant Group for their cooperation in providing data about their members, and would to thank the members of the group who took from their valuable time to complete the questionnaire. No funds were obtained for the study.

\section{Author details}

'Department of Oral and Maxillofacial Surgery, Oral Medicine, Oral Pathology, and Periodontology, Faculty of Dentistry, The University of Jordan, Amman, Jordan. Dental Department, The Islamic Hospital, Amman, Jordan. ${ }^{3}$ Faculty of Dentistry, The University of Jordan, Amman, Jordan.

\section{Authors' contributions}

All authors had reviewed and accepted the final manuscript. AA contribution was in literature review, designing the study, data analysis, write up and editing; KAA contributed in designing the study; $\mathrm{AK}, \mathrm{NK}, \mathrm{HH}$ contributed in collecting and entering data; $\mathrm{AH}$ contribution was in write up and editing and FS contributed in data analysis.

\section{Competing interests}

The authors declare that they have no competing interests.

Received: 5 May 2011 Accepted: 28 July 2011 Published: 28 July 2011

\section{References}

1. Ng PC, Pow EH, Ching SH, Lo EC, Chow TW: Dental implant practice among Hong Kong general dental practitioners in 2004 and 2008. Implant Dent 2011, 20(1):95-105.

2. Narby $B$, Kronström M, Söderfeldt B, Palmqvist $S$ : Changes in attitudes toward desire for implant treatment: a longitudinal study of a middleaged and older Swedish population. Int J Prosthodont 2008, 21(6):481-485.

3. Gianserra R, Cavalcanti R, Oreglia F, Manfredonia MF, Esposito M: Outcome of dental implants in patients with and without a history of periodontitis: a 5-year pragmatic multicentre retrospective cohort study of 1727 patients. Eur J Oral Implantol 2010, 3(4):307-314.

4. Cho-Lee GY, Naval-Gias L, Castrejon-Castrejon S, Capote-Moreno AL, Gonzalez-Garcia R, Sastre-Perez J, Munoz-Guerra MF: A 12-year retrospective analytic study of the implant survival rate in 177 consecutive maxillary sinus augmentation procedures. Int J Oral Maxillofac Implants 2010, 25(5):1019-1027.

5. Zinner ID, Markovits S, Jansen CE, Shapiro HJ, Reid PE: Solutions to complications of implant therapy. Gen Dent 2010, 58(5):416-422.

6. Rousseau P: Flapless and traditional dental implant surgery: an open, retrospective comparative study. J Oral Maxillofac Surg 2010, 68(9):2299-2306.

7. Simonis $P$, Dufour $T$, Tenenbaum H: Long-term implant survival and success: a 10-16-year follow-up of non-submerged dental implants. Clin Oral Implants Res 2010, 21(7):772-777.

8. Levin L: Dealing with dental implant failures. Refuat Hapeh Vehashinayim 2010, 27(1):6-12, 73

9. Esposito M, Grusovin MG, Tzanetea E, Piattelli A, Worthington HV: Interventions for replacing missing teeth: treatment of perimplantitis. Cochrane Database Syst Rev 2010, 16(6):CD004970.

10. Esposito M, Thomsen P, Ericsson LE, Lekholm U: Histopathologic observations on early oral implant failures. Int J Oral Maxillofac Implants 1999, 14:798-810.

11. Morris HF, Ochi S, Plezia R, Gilbert H, Dent CD, Pikulski J, Lambert PM: AICRG, Part III: The influence of antibiotic use on the survival of a new implant design. J Oral Implantol 2004, 30(3):144-151.

12. Anitua E, Aguirre JJ, Gorosabel A, Barrio P, Errazquin JM, Román P, Pla R, Carrete J, de Petro J, Orive G: A multicentre placebo-controlled randomised clinical trial of antibiotic prophylaxis for placement of single dental implants. Eur J Oral Implantol 2009, 2(4):283-292.
13. Mazzocchi A, Passi L, Moretti R: Retrospective analysis of 736 implants inserted without antibiotic therapy. J Oral Maxillofac Surg 2007, 65(11):2321-2323.

14. Dent CD, Olson JW, Farish SE, Bellome J, Casino AJ, Morris HF, Ochi S: The influence of preoperative antibiotics on success of endosseous implants up to and including stage II surgery: a study of 2,641 implants. J Oral Maxillofac Surg 1997, 55(Suppl 5):19-24.

15. Laskin DM, Dent CD, Morris HF, Ochi S, Olson JW: The influence of preoperative antibiotics on success of endosseous implants at 36 months. Ann Periodontol 2000, 5(1):166-174.

16. Caiazzo A, Casavecchia P, Barone R, Brugnami F: A Pilot study to determine the effectiveness of different amoxicillin regimens in implant surgery. J Oral Implantol 2010.

17. Gynther GW, Kondell P, Moberg LE, Heimdahl A: Dental implant installation without antibiotic prophylaxis. Oral Surg Oral Med Oral Pathol Oral Radiol Endod 1998, 85:509-111.

18. Binahmed A, Stoykewych A, Peterson L: Single preoperative dose versus long-term prophylactic antibiotic regimens in dental implant surgery. Int J Oral Maxillofac Implants 2005, 20:115-117.

19. Abu karaky A, Sawair F, Al-Karadsheh O, Eimar H, Algarugly S, Baqain Z: Antibiotic prophylaxis and early dental implant failure: a quasi-random controlled clinical trial. Eur J Oral Implantol 2011, 4(1):31-38.

20. Arason VA, Sigurdsson JA: The problems of antibiotic overuse. Scand J Prim Health Care 2010, 28(2):65-66.

21. Faure $H$, Mahy S, Soudry A, Duong M, Chavanet $P$, Piroth L: Factors influencing the prescription or non-prescription of antibiotics by general practitioners. Med Mal Infect 2009, 39(9):714-721, French.

22. Strand J, Rokstad KS, Sandvik H: Prescribing systemic antibiotics in general practice. A report from the Møre \& Romsdal Prescription Study. Scand Prim Health Care 1998, 16(2):121-127.

23. Otters HB, vander Wouden JC, Schellevis FG, van Suijlekom-Smit LW, Koes BW: Trends in prescribing antibiotics for children in Dutch general practice. J Antimicrob Chemother 2004, 53(2):361-366.

24. Wächtler $\mathrm{H}$, Chenot JF: Guidelines for the management of sore throat from the German Society of General Practice and Family Medicine. HNO German; 2011

25. Chiappini E, Regoli M, Bonsignori F, Sollai S, Parretti A, Galli L, de Martino M: Analysis of different recommendations from international guidelines for the management of acute pharyngitis in adults and children. Clin Ther 2011, 33(1):48-58.

26. Yu VL: Guidelines for hospital-acquired pneumonia and health-careassociated pneumonia: a vulnerability, a pitfall, and a fatal flaw. Lancet Infect Dis 2011, 11(3):248-252.

27. Kwon JG, Park KS, Park JH, Park JM, Park CH, Lee KJ, Park HJ, Rhee JC: The Korean Society of Neurogastroenterology and Motility: Guidelines for the Treatment of Irritable Bowel Syndrome. In Korean J Gastroenterol. Volume 57. Korean; 2011:(2):82-99.

28. Keltai K, István G, Katalin G, Mihály $\mathrm{O}$ : New guidelines on the prevention of infective endocarditis. Special aspects for dentists. In Fogorv Sz. Volume 103. Hungarian; 2010:(4):115-118

29. Freifeld AG, Bow EJ, Sepkowitz KA, Boeckh MJ, Ito JI, Mullen CA, Raad II, Rolston KV, Young JA, Wingard JR: Clinical practice guideline for the use of antimicrobial agents in neutropenic patients with cancer: 2010 update by the infectious diseases society of america. Clin Infect Dis 2011. 52(4):e56-93.

30. Ellervall $E$, Vinge $E$, Rohlin $M$, Knutsson $K$ : Antibiotic prophylaxis in oral healthcare - the agreement between Swedish recommendations and evidence. Br Dent J 2010, 208(3):E5, discussion 114-115.

31. Lyon DJ, Scheel O, Fung KSC, Cheng AFB, Henrichsen J: Rapid emergence of penicillin-resistant pneumococci in Hong Kong. Scand J Infect Dis 1996 28:375-376.

32. Classen DC, Evans RS, Pestotnik SL, Horn SD, Menlove RL, Burke JR: The timing of prophylactic administration of antibiotics and the risk of surgical-wound infection. N Engl J Med 1992, 326:281-286.

33. Sawair FA: Antibiotic prescription by general dental practitioners in the management of acute dentoalveolar infections. Saudi Dental Journal 2006, 18(2):111-117.

34. Lambrecht JT, Cardone E, Kühl S: Status report on dental implantology in Switzerland in 2006. A cross-sectional survey. Eur J Oral Implantol 2010, 3(1):71-74 
35. Esposito M, Grusovin MG, Coulthard P, Oliver R, Worthington HV: The efficacy of antibiotic prophylaxis at placement of dental implants: a Cochrane systematic review of randomised controlled clinical trials. Eur $\lrcorner$ Oral Implantol 2008, 1(2):95-103.

36. Esposito M, Grusovin MG, Loli V, Coulthard P, Worthington HV: Does antibiotic prophylaxis at implant placement decrease early implant failures? A Cochrane systematic review. Eur J Oral Implantol 2010, 3(2):101-110

37. Mestnik MJ, Feres M, Figueiredo LC, Duarte PM, Lira EA, Faveri M: Shortterm benefits of the adjunctive use of metronidazole plus amoxicillin in the microbial profile and in the clinical parameters of subjects with generalized aggressive periodontitis. J Clin Periodontol 2010, 37(4):353-365.

38. Yek EC, Cintan S, Topcuoglu N, Kulekci G, Issever H, Kantarci A: Efficacy of amoxicillin and metronidazole combination for the management of generalized aggressive periodontitis. J Periodontol 2010, 81(7):964-974.

39. Cionca N, Giannopoulou C, Ugolotti G, Mombelli A: Microbiologic testing and outcomes of full-mouth scaling and root planing with or without amoxicillin/metronidazole in chronic periodontitis. J Periodontol 2010, 81(1):15-23.

doi:10.1186/1756-0500-4-266

Cite this article as: AbuKaraky et al:: Antibiotics prescribing practices in oral implantology among jordanian dentists. A cross sectional, observational study. BMC Research Notes 2011 4:266.

\section{Submit your next manuscript to BioMed Central} and take full advantage of:

- Convenient online submission

- Thorough peer review

- No space constraints or color figure charges

- Immediate publication on acceptance

- Inclusion in PubMed, CAS, Scopus and Google Scholar

- Research which is freely available for redistribution

Submit your manuscript at www.biomedcentral.com/submit
Biomed Central 